\title{
Reports
}

\section{The importance of motivation, weapons, and foul odors in driving encounter competition in carnivores}

\author{
Maximilian L. Allen, $, 1,2,3,6$ Christopher C. Wilmers, ${ }^{1}$ L. Mark Elbroch, ${ }^{4}$ Julie M. Golla,${ }^{5}$ And \\ Heiko U. WitTMER ${ }^{2}$ \\ ${ }^{1}$ Center for Integrated Spatial Research, Environmental Studies Department, University of California, Santa Cruz, California 95064 \\ USA \\ ${ }^{2}$ School of Biological Sciences, Victoria University of Wellington, PO Box 600, Wellington, 6140 New Zealand \\ ${ }^{3}$ Department of Forest and Wildlife Ecology, University of Wisconsin, 1630 Linden Drive, Madison, Wisconsin 53706 USA \\ ${ }^{4}$ Panthera Puma Program, Panthera, 18th Floor, 8 W 40th St, New York, New York 10018 USA \\ ${ }^{5}$ College of Natural Resources, Utah State University, College of Natural Resources, Utah State University, 5200 Old Main Hill, \\ Logan, Utah 84322 USA
}

\begin{abstract}
Encounter competition is interference competition in which animals directly contend for resources. Ecological theory predicts the trait that determines the resource holding potential (RHP), and hence the winner of encounter competition, is most often body size or mass. The difficulties of observing encounter competition in complex organisms in natural environments, however, has limited opportunities to test this theory across diverse species. We studied the outcome of encounter competition contests among mesocarnivores at deer carcasses in California to determine the most important variables for winning these contests. We found some support for current theory in that body mass is important in determining the winner of encounter competition, but we found that other factors including hunger and species-specific traits were also important. In particular, our top models were "strength and hunger" and "size and hunger," with models emphasizing the complexity of variables influencing outcomes of encounter competition. In addition, our wins above predicted (WAP) statistic suggests that an important aspect that determines the winner of encounter competition is species-specific advantages that increase their RHP, as bobcats (Lynx rufus) and spotted skunks (Spilogale gracilis) won more often than predicted based on mass. In complex organisms, such as mesocarnivores, species-specific adaptations, including strategic behaviors, aggressiveness, and weapons, contribute to competitive advantages and may allow certain species to take control or defend resources better than others. Our results help explain how interspecific competition shapes the occurrence patterns of species in ecological communities.
\end{abstract}

Key words: California; carrion; encounter competition; foraging arenas; interference competition; interspecific interactions; mesocarnivore.

\section{INTRODUCTION}

Encounter competition occurs when animals directly contend for resources, and one of the competitors suffers "harm" such as loss of feeding opportunities or energy, injury, or death (Schoener 1983). Such contests over resources often involve fighting (e.g., Dickman 1991), and previous work indicates that the winner of these contests is most frequently determined by body size or mass (Connell 1983, Schoener 1983, Donadio and Buskirk 2006). The ability of an individual to win a contest for a valuable resource is referred to as its resource holding potential

Manuscript received 26 November 2015; revised 15 February 2016; accepted 29 April 2016. Corresponding Editor: E. T. Borer. 6E-mail: maximilian.allen@wisc.edu
(RHP, Briffa and Sneddon 2007). Aside from size, other traits can determine RHP and therefore the outcome of encounter competition between animals of asymmetric size (Courtene-Jones and Briffa 2014, Martin and Ghalambor 2014). Certain species or individuals may be more aggressive than others, while others have developed specialized weapons or defenses (Courtene-Jones and Briffa 2014, Martin and Ghalambor 2014). These should theoretically allow individuals to overcome a certain amount of size differential, yet direct tests of interspecific contests in the wild are few. Therefore traits other than size should be considered to better comprehend outcomes of encounter competition contests in complex organisms including vertebrates (e.g., Briffa and Sneddon 2007, Martin and Ghalambor 2014). Determining the various factors that 
drive the outcome of encounter competition will help in better understanding the evolution of behavior as well as the forces structuring ecological communities.

Encounter competition occurs rarely and unpredictably, and is thus difficult to observe in natural environments; this is especially true for cryptic species, such as carnivores. Previous research on the subject has relied upon laboratory experiments and easily observed species inhabiting open habitats to develop theory (Schoener 1983, Johnson et al. 1985, Cooper 1991, Dickman 1991). This bias may have influenced our current perceptions on encounter competition, which emphasizes "bigger is better" even in complex organisms with diverse adaptations (Martin and Ghalambor 2014). This bias may be especially relevant in mesocarnivores, highly adapted predators that occasionally fall prey to bigger predators themselves (Polis and Holt 1992, Palomares and Caro 1999, Donadio and Buskirk 2006). Their unique positions as predators and prey have led to distinctive adaptations and ecological niches. For example, the chemical weapons of skunks, which are traditionally associated with defense (Hunter 2009), could also prove advantageous during encounter competition (e.g., Martin and Ghalambor 2014).

Mesocarnivores commonly interact over important sources of food, including carrion (Wilmers et al. 2003, Selva et al. 2005, Allen et al. 2014). Competition may increase when resources, such as carrion, are limited (Wiens 1977, Palomares and Caro 1999) or highly valued (Tanner and Adler 2009), or when niche overlap among competitors is high (Case and Gilpin 1974, Schoener 1983). Carrion is also generally stationary, which allows for repeated intra- and inter-specific encounter competition contests at a given carcass, and allows for prolonged assessment. Because animals repeatedly compete for carrion resources, it suggests that encounter competition contests among mesocarnivores at carrion may not solely depend on body size or mass. Instead, species might be testing each other or relying on other traits and factors that might influence the winner of these contests (e.g., Martin and Ghalambor 2014). These factors may include order of arrival at the carcass, which animal is defending the carcass, and the motivation (i.e., hunger) and health of the individuals involved. Therefore, determining the winner of interspecific encounter competition contests among mesocarnivores may prove complex in natural systems.

In order to test the ecological theory underlying encounter competition, we compared the importance of size versus other traits in determining a species' RHP in interspecific contests. We created foraging arenas (Ahrens et al. 2012), in the form of black-tailed deer (Odocoileus hemionus columbianus) carcasses, and recorded the outcomes of interspecific contests among mesocarnivores with motion-triggered video cameras. We quantified the animal's mass and seven other variables, including health, hunger, and whether the animal was defending the carcass to determine if they contributed to winning contests. We then tested the variables both separately and together in multivariate models to test existing ecological theory and determine if factors other than mass predicted winners in interspecific encounter competition within a mesocarnivore guild.

\section{Materials And Methods}

\section{Study area}

We conducted our study in an area of approximately $1024 \mathrm{~km}^{2}$ in and adjacent to the Mendocino National Forest, California (Fig. 1). Characteristics of the study area, including topography, climate, and habitat composition, have been described in detail in Allen et al. (2014). The area supported two large carnivores, the puma (Puma concolor) and black bear (Ursus americanus), and a diverse community of mesocarnivores including gray foxes (Urocyon cinereoargenteus), coyotes (Canis latrans), bobcats (Lynx rufus), western spotted skunks (Spilogale gracilis), fishers (Martes pennanti), ringtails (Bassariscus astutus), and raccoons (Procyon lotor).

\section{Field methods}

We collected road-killed black-tailed deer from highways in Mendocino, Lake, Glenn, Sonoma, and Marin counties. We only collected deer in good condition, with clear, unclouded eyes, no discoloration in the abdominal region, and no obvious external wounds. As requested by California Fish and Wildlife to minimize the transmission of disease, we removed the head and internal organs before placing the carcasses in the field for our experiments. We placed each carcass in its entirety $(n=100)$ or cut in half $(n=71)$ stratified across different habitats. We anchored each carcass to a tree with a metal cable, and mounted a motion-triggered camera on a nearby tree. The cameras were set to record the maximum amount of video: Cuddeback IR cameras ( $n=112$; Cuddeback IR, De Pere, Wisconsin, USA) were set to take one photo and a 30 -s video with a 1-min delay between triggers, while Bushnell cameras $(n=59$; Bushnell ScoutCam, Overland Park, Kansas, USA) were set to record a 60 -s video with a 1-s delay between triggers. We removed the cameras after three weeks or when there were no longer edible remains.

We examined each video where an encounter occurred between mesocarnivores and evaluated the encounter to determine a winner and loser. Encounters were split into two types of contests: direct encounters $(n=33)$ and "push-offs" $(n=27)$. We defined direct encounters as interactions in which two animals directly interacted in the video. We defined push-offs as contests in which one animal left the carcass within $10 \mathrm{~min}$ of the arrival of another species, and when the arrival of the second animal was likely the reason for the first species leaving. In push-off encounters we only used encounters that were characterized by apprehensive or agitated body language in the animal leaving, or aggressive body language in the 


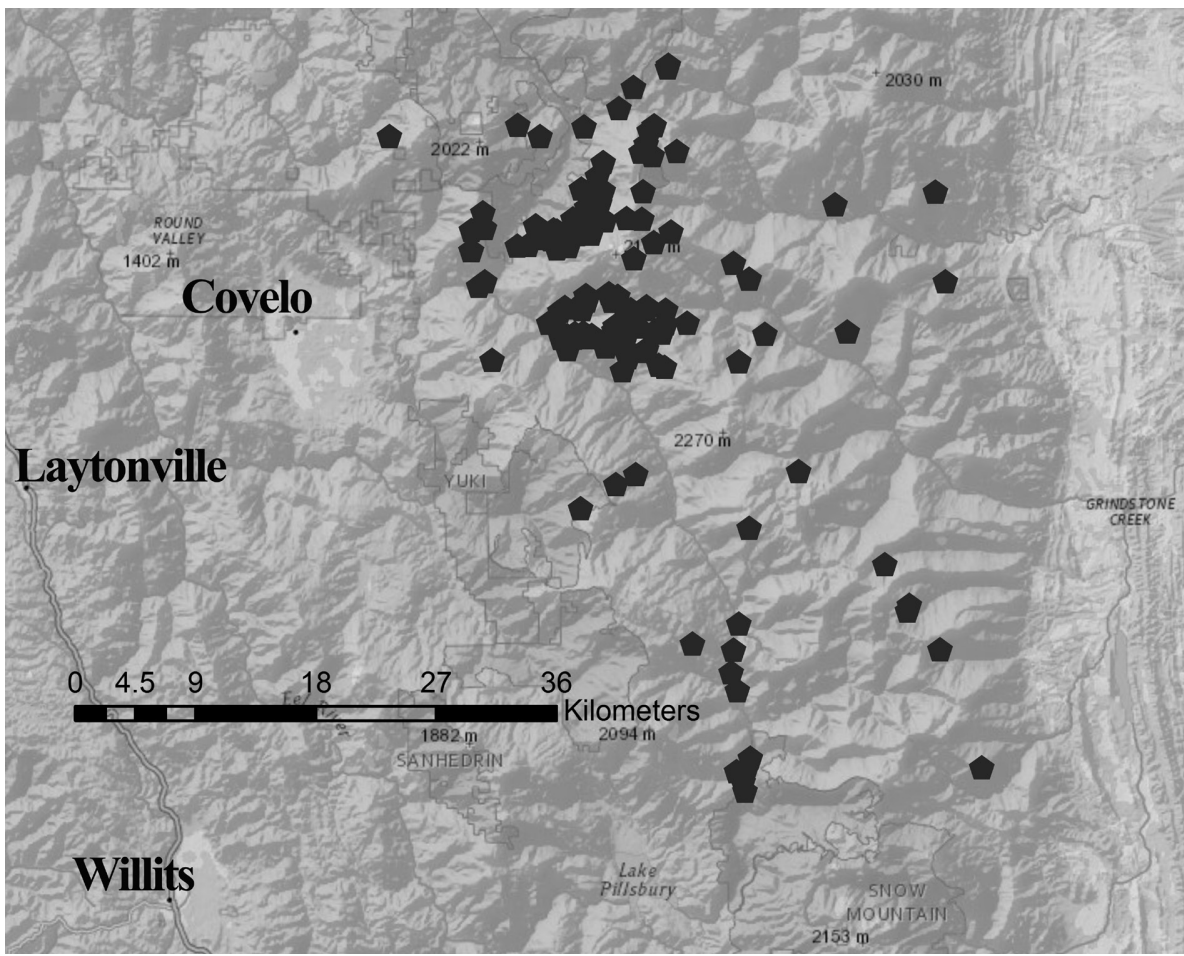

FIG. 1. A map of the study area, in Mendocino National Forest in the North Coast Range of California, USA. The location of each of the 171 carcasses used to document encounter competition among mesocarnivores is noted.

animal arriving, in order to eliminate spurious data from passive encounters during which a subdominant animal may have fed while the dominant animal was absent. We defined the winner of each encounter competition contest as the species that controlled the carcass and was able to feed at the end of the encounter; with each encounter being recorded as a win, a loss, or a tie. In the event of a tie, where both animals fed at the same time, the contest was

TABLE 1. The individual variables tested to predict the winner of encounter competition contests.

\begin{tabular}{|c|c|c|c|c|c|c|}
\hline Name & Abbreviation & Unit & Description & Coefficient & $P$ value & $C$ score \\
\hline Mass & MASS & $\mathrm{kg}$ & the mass of the given species & 0.0547 & 0.16 & 0.57 \\
\hline Mass differential & MSDF & $\mathrm{kg}$ & $\begin{array}{l}\text { the difference in mass between } \\
\text { the given species and the } \\
\text { species it is competing with }\end{array}$ & 0.1233 & $<0.01$ & 0.67 \\
\hline Number of individuals & NUMB & number & $\begin{array}{l}\text { the number of individuals of the } \\
\text { species present during the event }\end{array}$ & -0.9400 & 0.29 & 0.52 \\
\hline Total time & TOTM & minutes & $\begin{array}{l}\text { the total time the species spent at } \\
\text { the carcass }\end{array}$ & -0.0001 & 0.83 & 0.47 \\
\hline Time before encounter & TBEN & minutes & $\begin{array}{l}\text { the total time the species spent at } \\
\text { the carcass before the } \\
\text { encounter occurred }\end{array}$ & -0.0016 & 0.22 & 0.52 \\
\hline Visit duration & VSDR & minutes & $\begin{array}{l}\text { the duration of the current visit } \\
\text { for the species at the carcass } \\
\text { before the event occurred }\end{array}$ & -0.2886 & $<0.01$ & 0.78 \\
\hline Discoverer & DSCR & 0 or 1 & $\begin{array}{l}\text { whether this species discovered } \\
\text { the carcass before the other } \\
\text { species }\end{array}$ & -1.1056 & $<0.01$ & 0.64 \\
\hline Controller & CONT & 0 or 1 & $\begin{array}{l}\text { was the species in control of the } \\
\text { carcass when the encounter } \\
\text { occurred }\end{array}$ & -1.5581 & $<0.01$ & 0.69 \\
\hline Health of animal & HLTH & 0 or 1 & $\begin{array}{l}\text { was there any noticeable injury } \\
\text { or abnormal about the animal }\end{array}$ & -1.2295 & 0.03 & 0.52 \\
\hline
\end{tabular}


TABLE 2. The base of the multi-variate models we tested to determine which hypotheses best explained the winner of interspecific encounter competition contests.

\begin{tabular}{|c|c|c|c|}
\hline Name & Hypothesis & Reason & Variables \\
\hline Size & $\begin{array}{l}\text { The size of the animals will be } \\
\text { the most important influence. }\end{array}$ & $\begin{array}{l}\text { Animals of larger size will have an } \\
\text { advantage over smaller animals, and that } \\
\text { will determine who wins encounters. }\end{array}$ & MASS $\times$ MSDF \\
\hline Strength & $\begin{array}{l}\text { Animals with greater physical } \\
\text { strength will be more likely to } \\
\text { win. }\end{array}$ & $\begin{array}{l}\text { The size, health, and number of animals } \\
\text { will be the most important influence of } \\
\text { who wins an encounter. }\end{array}$ & $\mathrm{MSDF} \times \mathrm{NUMB} \times \mathrm{HLTH}$ \\
\hline Hunger & $\begin{array}{l}\text { Animals that are hungry will be } \\
\text { more aggressive and less likely } \\
\text { to cede the carcass to another. }\end{array}$ & $\begin{array}{l}\text { Animals that are hungry will be more } \\
\text { willing to engage others and risk injury, } \\
\text { and this will make them more likely to } \\
\text { win encounters. }\end{array}$ & $\mathrm{VSDR} \times \mathrm{TBEN}$ \\
\hline Defense & $\begin{array}{l}\text { Animals defending the carcass } \\
\text { will be more likely to win. }\end{array}$ & $\begin{array}{l}\text { The animal that is defending the carcass } \\
\text { will have an advantage, and this will } \\
\text { increase in cold weather with higher } \\
\text { metabolic need. }\end{array}$ & $\mathrm{DFND} \times \mathrm{TEMP}$ \\
\hline
\end{tabular}

considered a win for each species in our statistical models, as they both received energetic gain. We provide the pairings of species in all contests in Appendix S1: Table S1.

For each encounter we then quantified eight variables (Table 1) to determine the best predictors of winners in encounter competition contests between mesocarnivores. We determined "mass" for each species from the mean body mass reported by Jameson and Peeters (2004). We then calculated "mass differential" based on the difference in body mass between the two species in a given encounter, with the large species given a positive number and the smaller species a negative number. We determined "number of individuals" by how many individuals of each species were present in the encounter. We determined "total time" as the sum amount of time that each species spent at the given carcass to the closest minute. We calculated "time before encounter" as the combined time for all visits the first species spent at the carcass before the encounter occurred, and "visit duration" as the amount of time during the specific visit the first species was present at the carcass before the encounter occurred. We defined the "defender" as the species that was currently feeding and hence defending the carcass when the encounter occurred. We noted "health" as either positive or negative, with negative used when an individual animal had a noticeable injury. We calculated "temperature" as the mean daily temperature in the study area for the day of the encounter using data available from National Oceanic and Atmospheric Administration (Mendocino Pass, California weather station).

\section{Statistical analyses}

We used program R version 3.0.0 (R Core Team 2013) for all statistical analyses, and following $\mathrm{R}$ guidelines, we cited any associated packages used in analyses. We employed an a priori approach to first test the influence of select individual covariates of biological importance. Second, we proceeded with meaningful combinations of these covariates to test more complex ecological questions (Table 2). We employed generalized linear models with a binomial link in the rms package (Harrell 2013). We used win/loss as our binomial dependent variable, and first used each of the variables in turn as our independent variable, before progressing to multivariate models.

We determined the best predictors among individual variables using their $P$ values and $C$ index scores (Hosmer and Lemeshow 2000), and considered $C$ index scores of 0.8 to be strong, and 0.6 to be relatively strong. For each of our multivariate models, we calculated Akaike's Information Criterion (hereafter AIC) scores (Akaike 1974), and used AIC weights $\left(\mathrm{AIC}_{\mathrm{w}}\right)$ to compare models to each other. We considered the top model and any subsequent model differing by $<4 \Delta \mathrm{AIC}$ units to have produced substantial empirical support for explaining variation in the dependent variable, and any model within 4-7 $\triangle \mathrm{AIC}$ units of the top model to have produced considerably less support, but to still hold biological information potentially relevant for ecological interpretation (Burnham and Anderson 2002). For each variable in our biologically relevant models, we then provided their coefficient, odds ratio, and we calculated their Cohen's $d$ score as follows:

$$
d=\operatorname{LogOddsRatio} \times \frac{\sqrt{3}}{p i}
$$

as suggested by Sanchez-Meca et al. (2003).

In order to understand species-specific trends in encounter competition contests, we calculated a post hoc statistic we termed "Wins Above Predicted" (WAP) for each mesocarnivore species recorded. For each species, we calculated a predicted score and an actual score, assigning a point value $(2=$ win, $1=$ tie, $0=$ loss $)$ for the outcome of each encounter. Our predicted values were based on encounter competition theory that predicts that the species with greater body mass will win encounter competition contests (Connell 1983, Schoener 1983). The species final WAP score was then the difference between these predicted and actual scores. 

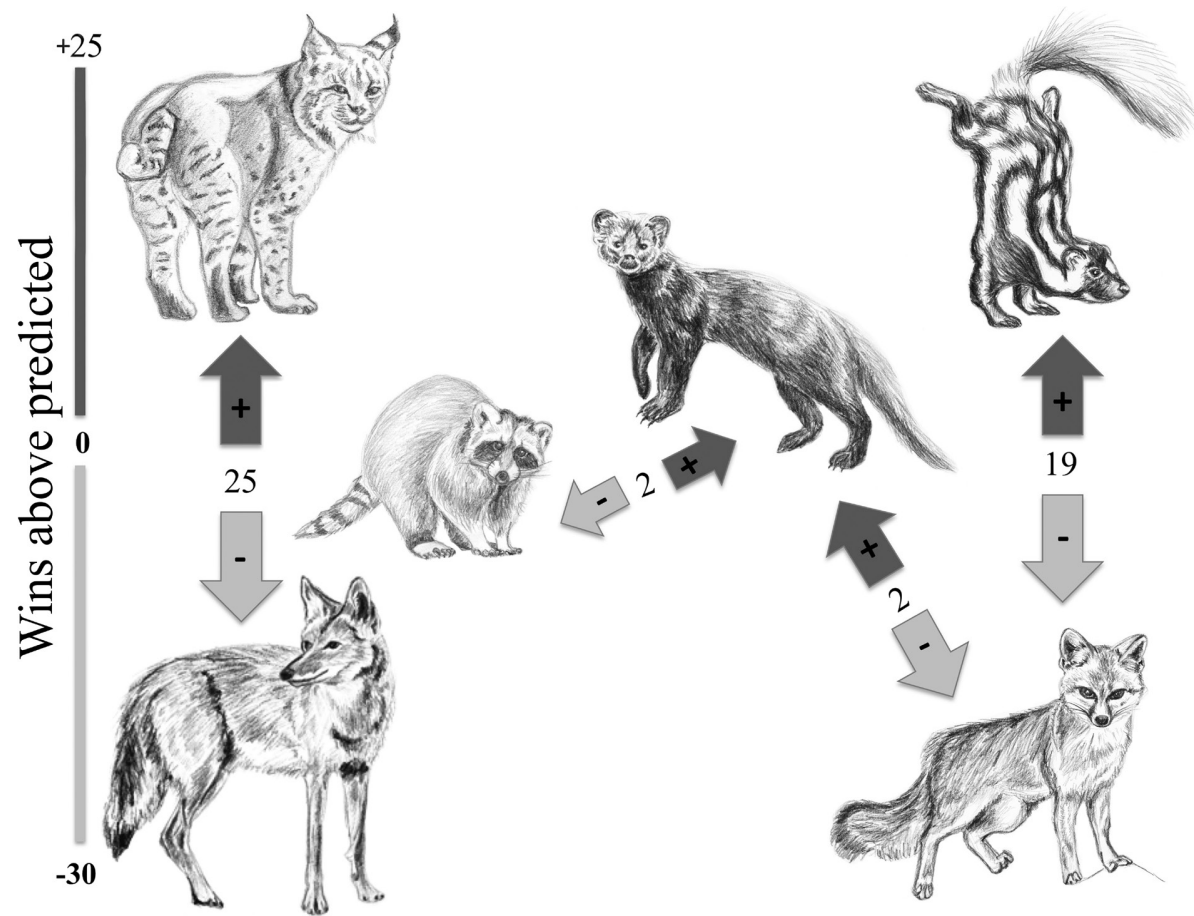

FIG. 2. An illustrative figure of the dynamics of encounter competition between specific species. The difference between actual and predicted wins are noted on the lines between species. The two interspecific interactions most driving our results were bobcats winning more often over coyotes than predicted, and spotted skunks winning more often over gray foxes than predicted.

\section{RESULTS}

We recorded a total of 27,314 videos at black-tailed deer carcasses, and documented 60 interspecific encounter competition contests among mesocarnivores. Species involved in contests included gray fox $(n=31)$, coyote $(n=28)$, bobcat $(n=27)$, western spotted skunk $(n=16)$, fisher $(n=13)$, ringtail $(n=3)$, and raccoon $(n=2)$.
The best significant predictor of winning an encounter competition contest among individual variables was "visit duration" $(P<0.01, C=0.78)$, the only variable with a strong correlation (Table 1). This suggests that animals that had been feeding for relatively short durations were more likely to win, as they wanted to continue to feed. Other variables with significant and moderately strong correlations included:

TABLE 3. The results from our comparisons of competition models.

\begin{tabular}{|c|c|c|c|c|c|}
\hline Name & Model & $C$ index & $\mathrm{AIC}_{\mathrm{c}}$ & $\Delta \mathrm{AIC}$ & $\mathrm{AIC}_{\mathrm{w}}$ \\
\hline Strength and hunger & $\mathrm{MSDF}+\mathrm{NUMB}+\mathrm{HLTH}+\mathrm{VSDR}+\mathrm{TBEN}$ & 0.80 & 142.6 & 0 & 0.73 \\
\hline Size and hunger & VSDR + TBEN + MASS + MSDF & 0.79 & 145.4 & 2.8 & 0.18 \\
\hline Hunger and control & $\mathrm{VSDR}+\mathrm{TBEN}+\mathrm{CONT}+\mathrm{TEMP}$ & 0.77 & 148.5 & 5.9 & 0.04 \\
\hline Hunger & VSDR + TBEN & 0.77 & 149.0 & 6.4 & 0.03 \\
\hline Investment and control & DSCR + TOTM + TEMP + CONT & 0.74 & 150.8 & 8.2 & 0.01 \\
\hline Strength and control & CONT + TEMP + MSDF + HLTH + NUMB & 0.77 & 151.6 & 9 & 0.01 \\
\hline Control & CONT + TEMP & 0.70 & 154.4 & 11.8 & 0.00 \\
\hline Size and control & $\mathrm{CONT}+\mathrm{TEMP}+\mathrm{SIZE}+\mathrm{MSDF}$ & 0.73 & 155.2 & 12.6 & 0.00 \\
\hline Strength & MSDF + NUMB + HLTH & 0.71 & 156.7 & 14.1 & 0.00 \\
\hline Strength and investment & $\mathrm{DSCR}+\mathrm{TOTM}+\mathrm{TEMP}+\mathrm{MSDF}+\mathrm{NUMB}+\mathrm{HLTH}$ & 0.72 & 156.9 & 14.3 & 0.00 \\
\hline Size and investment & DSCR + TOTM + TEMP + MASS + MSDF & 0.73 & 157.4 & 14.8 & 0.00 \\
\hline Size & MASS $\times$ MSDF & 0.70 & 158.1 & 15.5 & 0.00 \\
\hline Investment & DSCR + TOTM + TEMP & 0.65 & 164.3 & 21.7 & 0.00 \\
\hline
\end{tabular}

Notes: For each model we report the variables in the model, the $C$ index score, and the Akaike information criterion weight $\left(\mathrm{AIC}_{\mathrm{w}}\right)$. We determined the best model through comparison of AIC weights. 
TABLE 4. The contributions of individual variables for our four biologically relevant models.

\begin{tabular}{lrrr}
\hline \hline Variables & Coefficient & Odds ratio & $D$ \\
\hline Strength and hunger & & & \\
Intercept & 2.9887 & 19.8598 & - \\
MSDF & 0.1236 & 1.1316 & 0.07 \\
NUMB & -2.2461 & 0.1058 & -1.24 \\
HLTH & 2.9887 & 1.2513 & 0.12 \\
VLNT & 0.1236 & 0.7665 & -0.15 \\
TBEN & -0.0016 & 0.9984 & 0.00 \\
Size and hunger & & & \\
Intercept & 1.1342 & 3.1087 & - \\
VLNT & -0.2548 & 0.7751 & -0.14 \\
TBEN & -0.0011 & 0.9989 & 0.00 \\
MASS & -0.0544 & 0.9471 & -0.03 \\
MSDF & 0.1232 & 1.1311 & 0.07 \\
Hunger and control & & & \\
Intercept & 1.1711 & 3.2255 & - \\
VLNT & -0.2117 & 0.8092 & -0.12 \\
TBEN & -0.0009 & 0.9991 & 0.00 \\
CONT & -0.9353 & 0.3925 & -0.52 \\
TEMP & -0.0062 & 0.9938 & 0.00 \\
Hunger & & & \\
Intercept & 0.7580 & 2.1340 & - \\
VLNT & -0.2868 & 0.7507 & -0.16 \\
TBEN & -0.0008 & 0.9992 & 0.00 \\
\hline
\end{tabular}

"defender" $(P<0.01, C=0.69)$, "mass differential" $(P<0.01, C=0.67)$, and "discoverer" $(P<0.01$, $C=0.64$; Fig. 2).

Our multivariate model comparisons identified two top models $(\triangle \mathrm{AIC}=3.2)$, and an additional two models that provided biologically relevant information $(\Delta \mathrm{AIC}<7$; Table 3$)$. Both "strength and hunger" and "size and hunger" produced considerable support for predicting the outcome of encounters. The complexity of variables in the top-ranked models (Table 4) emphasized that much more than size influenced the outcomes of encounter competition contests.
Our wins above predicted (WAP) statistic showed strong trends for four species (Table 5). Two species consistently won more often than predicted: bobcats (WAP $=+25)$ and spotted skunks (WAP $=+19$ ). Two species consistently lost more often than predicted: coyotes (WAP $=-27$ ) and gray foxes (WAP $=-19$ ). The WAP scores for these species were influenced by two interspecific pairings; bobcats won against coyotes during 12 encounter competition contests, and spotted skunks won against gray foxes during seven encounter competition contests (Fig. 2).

\section{DisCUSSION}

This is among the first extensive studies of encounter competition among mesocarnivores in North America, and extends our knowledge of encounter competition theory to interspecific contests and natural ecological systems with multiple carnivorous mammals. Our results show that body mass is not the only trait influencing the outcome of interspecific encounter competition, and that there are multiple traits that are important in determining the winner. For dominant species, the cost of encounter competition is low, while the value of gaining exclusive access to a resource tends to be high (Dickman 1991). Carrion is such a valuable source of nutrition that it may increase the motivation of subordinate species to directly compete for it (e.g., Connell 1983) despite the potential costs involved (Briffa and Sneddon 2007). Mesocarnivores are also highly adapted species with species-specific adaptations that include strategy, aggressiveness, and weapons that may influence the outcome of encounter competition contests (Martin and Ghalambor 2014). Indeed, our WAP statistic suggests that some species, including bobcats and spotted skunks, had advantages over other species despite their smaller mass.

The best models explaining which species won competitive encounters included "hunger" (the feeding time overall and during a specific feeding bout) and "strength" (mass differential, the number of individuals in a group, and significant injuries), while "hunger" was also part of the next best model. Body mass and the number of individuals clearly matter in determining the winner of

TABLE 5. The "wins above predicted" (WAP) for each of the seven mesocarnivores we recorded during encounter competition contests.

\begin{tabular}{|c|c|c|c|c|c|c|c|c|c|}
\hline \multirow[b]{2}{*}{ Species } & \multicolumn{4}{|c|}{ Predicted } & \multicolumn{4}{|c|}{ Actual } & \multirow[b]{2}{*}{ WAP } \\
\hline & Win & Loss & Tie & Points & Win & Loss & Tie & Points & \\
\hline Bobcat & 9 & 18 & 0 & 18 & 21 & 5 & 1 & 43 & +25 \\
\hline Spotted skunk & 0 & 16 & 0 & 0 & 7 & 4 & 5 & 19 & +19 \\
\hline Fisher & 0 & 13 & 0 & 0 & 2 & 11 & 0 & 4 & +4 \\
\hline Ringtail & 0 & 3 & 0 & 0 & 0 & 3 & 0 & 0 & 0 \\
\hline Raccoon & 2 & 0 & 0 & 4 & 1 & 1 & 0 & 2 & -2 \\
\hline Gray fox & 21 & 10 & 0 & 42 & 8 & 17 & 5 & 23 & -21 \\
\hline Coyote & 28 & 0 & 0 & 56 & 14 & 13 & 1 & 29 & -27 \\
\hline
\end{tabular}

Note: First are the predicted points based on the mass of the species competing, followed by their actual points, and their total WAP. 
encounter competition contests (e.g., Connell 1983, Schoener 1983), and may be an important evolutionary reason for sexual dimorphism where larger mass decides the RHP of intraspecific contests (Briffa and Sneddon 2007). The value of the resource being competed for also appears to matter. Food resources, especially those that are highly valued and only available for short duration like carrion (Wiens 1977, Tanner and Adler 2009), may encourage fierce interspecific encounter competition, as compared with resources like dens or refugia that may not translate across species. Our results suggested that the animal that was hungrier was also more motivated to expend energy to gain a carrion resource.

Our WAP statistic suggested that important aspects that determine the winner of interspecific encounter competition contests are species-specific advantages. Bobcats and spotted skunks won more encounters than were predicted based on size alone, while coyotes and gray foxes lost more encounters than expected. Their higher RHP appears to be linked to both behavioral traits and better weapons (i.e., hooked claws for grappling in addition to teeth for bobcats, chemical weapons for skunks), or simply an increased ability to defend carcasses than other species. For example, we observed bobcats attacking coyotes with their front claws, especially in cases where the bobcat was defending the carcass. Spotted skunk's chemical defenses and asymptomatic coloring (Hunter 2009) can also be used in offensive behaviors to increase their RHP and ability to win encounter competition contests (e.g., Courtene-Jones and Briffa 2014, Martin and Ghalambor 2014); skunks need not actually use their chemical weapons, but only need to be abundant enough that potential predators have learned the consequences of interacting with one (Hunter 2009). We observed skunks approaching gray foxes at carcasses, and foxes retreating 5-7 $\mathrm{m}$ from the carcass while the skunk fed. A spotted skunk was documented usurping a kill from a puma nearly 100 times its size (Allen et al. 2013), and so it is not surprising that they were able to win encounters with mesocarnivores such as gray foxes only eight times larger. The two species, coyotes and gray foxes, which lost more often than expected, are both canids, and this suggests that canids may have similar behavioral strategies. Alternatively, canids may simply be more risk averse because they have developed fewer weapons than other mesocarnivores, as they can only attack with their teeth, as opposed to the claws of bobcats or chemical attacks of skunks. Some species have developed traits to increase their RHP in interspecific encounter competition contests, including larger muscles and claws (Martin and Ghalambor 2014). In intraspecific contests as well, individuals of some species have developed strategies to increase their RHP despite their smaller size (Neems et al. 1990, Zamudio and Sinervo 2000). These adaptations are likely to shape the behavioral ecology of the species, including the mesocarnivores in our study.

Species or individuals that regularly lose interspecific encounter competition contests may experience fitness consequences (e.g., Briffa and Sneddon 2007, van der Meer et al. 2011), especially if they are losing resources that they acquired themselves. Our experiments were based on carrion, where the "loser" experienced a limited loss beyond the nutrition that could be gained from the resource itself and the time spent attempting to acquire it. An animal that actually kills prey, however, would suffer significant costs if they lost encounter competition contests that led to a loss of the resource (Krofel et al. 2012, Allen et al. 2015, Elbroch et al. 2015). In contrast, species can also respond positively to interspecific competition (e.g., Connell 1983). For example, even though gray foxes lost encounter competition contests more often than predicted, interspecific interactions may have led them to discover carrion resources they otherwise would not have found, leading to a net gain from the resource. Therefore, despite frequently losing encounter competition contests, interspecific interactions may lead to an increase in the acquisition of carrion.

Our study was based on a relatively small sample despite considerable efforts invested in the field. We recorded mesocarnivore encounter competition contests during only $0.0022 \%$ of videos recorded, although even this might be considered a high rate of return on our investment when compared with other research on the subject (e.g., Dickman [1991] did not record a single contest between insectivorous mammals in enclosures over $116 \mathrm{~h}$ of observation). Thus the use of motiontriggered video cameras at important resources, including carcasses, create foraging arenas (Ahrens et al. 2012) that may provide exceptional opportunities for the study of encounter competition in vertebrates in natural environments. Our small sample size could also be interpreted to mean that interspecific encounter competition contests were too costly to engage in frequently, as is the case for intraspecific contests as well (Briffa and Sneddon 2007). Certain species appeared to avoid encounters with specific species that were clearly dominant. For example, ringtails appeared to avoid encounters with any other carnivore whenever possible, leading to only two recorded contests. We also never recorded encounter competition between coyotes and gray foxes, which could be explained by the fact that coyotes are significant predators of gray foxes (Fedriani et al. 2000). That specific species pairings never occurred or were very rare, does support existing theory, and suggest "bigger is better" in some cases, as within families of mesocarnivores with morphologically similar weapons. We recorded more encounters between species of relatively similar size and overlapping diet (Donadio and Buskirk 2006), which may make the outcome less decided, and encourage interspecific competition for species to exploit their species-specific advantages.

Understanding spatial and temporal occupancy patterns of species is an important focus of many ecological studies (e.g., Lesmeister et al. 2015, Wang et al. 2015), and here we have informed that process through the creation of foraging arenas (Ahrens et al. 2012) to investigate the mechanisms underlying interspecific encounter 
competition. This is the first experimental study of interspecific encounter competition among mesocarnivores, extending our understanding of interspecific encounter competition based on studies involving invertebrates (e.g., Courtene-Jones and Briffa 2014). We found that, similar to other taxonomic groups, body mass is important, but this can be overshadowed by motivation and other species-specific traits such as weapons. Future studies should try to better understand the role of species-specific adaptations in encounter competition contests including possible evolutionary trade-offs (e.g., Martin and Ghalambor 2014), and understanding the strategies of subordinate species that allow them to exploit resources in the presence of dominant species. Our results suggest that access to important resources provides life-history benefits that outweigh risks of injury or death, and these results inform our understanding of the abundance and distribution patterns of species in ecological communities.

\section{ACKNOWLEDGMENTS}

The California Department of Fish and Wildlife and Victoria University of Wellington generously provided funding for the study. We thank D. Casady, B. Evans, and the numerous field technicians that helped with the project. V. Yovovich and two anonymous reviewers provided comments on previous drafts that greatly improved the manuscript.

\section{Literature Cited}

Ahrens, R. N. M., C. J. Walters, and V. Christensen. 2012 Foraging arena theory. Fish and Fisheries 13:41-59.

Akaike, H. 1974. A new look at statistical model identification. IEEE Transactions on Automatic Control 19:716-723.

Allen, M. L., L. M. Elbroch, and H. U. Wittmer. 2013. Encounter competition between a cougar, Puma concolor, and a western spotted skunk, Spilogale gracilis. Canadian Field-Naturalist 127:64-66.

Allen, M. L., L. M. Elbroch, C. C. Wilmers, and H. U. Wittmer. 2014. Trophic facilitation or limitation? Comparative effects of pumas and black bears on the scavenger community. PLoS ONE 9:e102257.

Allen, M. L., L. M. Elbroch, C. C. Wilmers, and H. U. Wittmer. 2015. The comparative effects of large carnivores on the acquisition of carrion by scavengers. American Naturalist 185:822-833.

Briffa, M., and L. U. Sneddon. 2007. Physiological constraints on contest behavior. Functional Ecology 27:627-637.

Connell, J. H. 1983. On the prevalence and relative importance of interspecific competition: evidence from field experiments. American Naturalist 122:661-696.

Cooper, S. M. 1991. Optimal hunting group size: the need for lions to defend their kills against loss to spotted hyenas. African Journal of Ecology 29:130-136.

Courtene-Jones, W., and M. Briffa. 2014. Boldness and asymmetric contests: role- and outcome-dependent effects of fighting in hermit crabs. Behavioral Ecology 25:1073-1082.

Dickman, C. R. 1991. Mechanisms of competition among insectivorous mammals. Oecologia 85:464-471.
Donadio, E., and S. W. Buskirk. 2006. Diet, morphology, and interspecific killing among carnivora. American Naturalist 167:524-536.

Elbroch, L. M., P. Lendrum, M. L. Allen, and H. U. Wittmer. 2015. Nowhere to hide: pumas, black bears, and competition refuges. Behavioral Ecology 26:247-254.

Fedriani, J. M., T. K. Fuller, R. M. Sauvajot, and E. C. York. 2000. Competition and intraguild predation among three sympatric carnivores. Oecologia 125:258-270.

Hosmer, D. W., and S. Lemeshow. 2000. Applied logistic regression. John Wiley and Sons, New York, New York, USA.

Hunter, J. S. 2009. Familiarity breeds contempt: effects of striped skunk color, shape, and abundance on wild carnivore behavior. Behavioral Ecology 20:1315-1322.

Jameson, E. W., and H. J. Peeters. 2004. Mammals of California. University of California Press, Oakland, California, USA.

Johnson, D. M., P. H. Crowley, R. E. Bohanan, C. N. Watson, and T. H. Martin. 1985. Competition among larval dragonflies: a field enclosure experiment. Ecology 66:119-128.

Krofel, M., I. Kos, and K. Jerina. 2012. The noble cats and the big bad scavengers: effects of dominant scavengers on solitary predators. Behavioral Ecology and Sociobiology 66:1297-1304.

Lesmeister, D. B., C. K. Nielsen, E. M. Schauber, and E. Hellgren. 2015. Spatial and temporal structure of a mesocarnivore guild in midwestern North America. Wildlife Monographs 191:1-61.

Martin, P. R., and C. K. Ghalambor. 2014. When David beats Goliath: the advantage of large size in interspecific aggressive contests declines over evolutionary time. PLoS ONE 9:e108741.

Neems, R. M., A. J. McLachlan, and R. Chambers. 1990. Body size and lifetime mating success of male midges (Diptera: Chironomidae). Animal Behaviour 40:648-652.

Palomares, F., and T. M. Caro. 1999. Interspecific killing among mammalian carnivores. American Naturalist 153:492-508.

Polis, G. A., and R. D. Holt. 1992. Intraguild predation - the dynamics of complex trophic interactions. Trends in Ecology \& Evolution 7:151-154.

Sanchez-Meca, J., F. Marin-Martinez, and S. Chacon-Moscoso. 2003. Effect-size indices for dichotomized outcomes in metaanalysis. Psychological Methods 8:448-467.

Schoener, T. W. 1983. Field experiments on interspecific competition. American Naturalist 122:240-285.

Tanner, C. J., and F. R. Adler. 2009. To fight or not to fight: context-dependent interspecific aggression in competing ants. Animal Behavior 77:297-305.

van der Meer, E., M. Moyo, G. S. A. Rasmussen, and H. Fritz. 2011. An empirical and experimental test of risk and costs of kleptoparasitism for African wild dogs (Lycaon pictus) inside and outside a protected area. Behavioral Ecology 22:985-992.

Wang, Y., M. L. Allen, and C. C. Wilmers. 2015. Mesopredator spatial and temporal responses to large predators and human development in the Santa Cruz Mountains of California. Biological Conservation 190:23-33.

Wiens, J. A. 1977. On competition and variable environments. American Scientist 65:590-597.

Wilmers, C. C., R. L. Crabtree, D. W. Smith, K. M. Murphy, and W. M. Getz. 2003. Trophic facilitation by introduced top predators: grey wolf subsidies to scavengers in Yellowstone National Park. Journal of Animal Ecology 72:909-916.

Zamudio, K. R., and B. Sinervo. 2000. Polygyny, mateguarding, and posthumous fertilization as alternative male mating strategies. Proceedings of the National Academy of Sciences USA 97:14427-14432. 